\title{
Paranasal Sinus Sarcoma
}

National Cancer Institute

\section{Source}

National Cancer Institute. Paranasal Sinus Sarcoma. NCI Thesaurus. Code C6849.

A malignant soft tissue neoplasm that arises from the paranasal sinus. 